\title{
Awareness of Visual Inspection with Acetic-Acid (VIA) In Cervical Cancer Screening Among Nurses in Kaduna - State, Nigeria
}

\author{
Balarabe, $\mathrm{F}^{1}$, Musa, $\mathrm{U}^{2}$, Chado, M.A ${ }^{2}$, Garba, S.N ${ }^{1}$, and Musa, H.A ${ }^{1}$ \\ ${ }^{I}$ Department of Nursing Science, Faculty of Medicine, Ahmadu Bello University Zaria . \\ ${ }^{2}$ Department of Physical and Health Education, Faculty of Education, Ahmadu Bello university Zaria.
}

\begin{abstract}
The study aims at assessing the awareness of visual inspection with acetic-acid in cervical cancer screening among health workers in secondary health care institutions of Kaduna state. An Ex-post facto design was used for the study. The study population comprises all nurses, midwives, and nurse-midwives working in all the secondary healthcare institutions of the state. The sample size used for the study was 300 using the Yamane sample size selection formula. The technique involved was stratified sampling method whereby the three existing senatorial zones served as strata. Each of the stratum was clustered according to the existing local government areas. A purposive sampling was further used to select nine local governments, three from each senatorial zone that have secondary health care institutions. A proportionate sampling was used to distribute questionnaire copies to the health workers. The instruments used for data collection was a questionnaire which was structured base on a modified likert scale to four point scale. Three hundred (300) questionnaire copies were administered out of which (297) were retrieved. The data collected was analyzed using one way analysis of variance (ANOVA) and two sample t- test at 0.05 level of confidence to answer the hypothesis. Findings from the study shows that nurses in secondary healthcare institutions of Kaduna-state are not aware of using VIA in cervical cancer screening with an aggregate mean score of (2.2288). There is significant difference in the demographic variables of (age-group, sex, professional category, and secondary health care institutions) in the awareness of VIA among nurses in Kaduna-state $(p<0.05)$. It was therefore recommended that the state hospitals management board in collaboration with the Nursing and Midwifery Council of Nigeria should mount awareness campaign for nurses through seminars and workshops to make them fully aware of the VIA.
\end{abstract}

Key words: Awareness, Visual inspection, Acetic-acid, Nurses.

\section{Introduction}

The World Health Organization (2013), reported that over the past few decades, 60\% of all deaths worldwide has been from chronic non-communicable diseases like cardiovascular diseases, cancer, chronic respiratory diseases and diabetes. Mortality due to communicable diseases has decreased, while there is increased in that of cancer and heart diseases. The cervical cancer incidence remains unchanged with about $44 \%$ overall survival rate or about 10 per 100,000 women dying from the disease over 5 years (WHO, 2013). In Nigeria, estimated incidence rate of cervical cancer is 25 out of 100,000 women with estimated 8000 new cases diagnosed each year (Adewole, Benedict, Brain and Follen, 2005). Equally, high rate of cervical cancer has been reported from several African countries including Uganda, Malawi, Ethiopia and Kenya (WHO, 2012). Cervical cancer is a malignant neoplasm arising from cells originating in the cervix uteri. The cervix is the narrow portion of the uterus where it joins with the top of the vagina, and most cervical cancers are squamous cell carcinomas, arising in squamous (flattened) epithelial cells that lie in the cervix. One of the most common symptoms of cervical cancer is abnormal vaginal bleeding but in some cases, there may be no obvious symptoms until the cancer has progressed to an advanced stage (Dim, 2012). In developed countries, the use of cytology screening has strongly reduced both cervical cancer incidence and mortality. Due to lack of technical skills, human resources and financing required, to maintain the screening procedure in developing countries, Nigeria inclusive, the need for visual inspection with acetic acid emerged as immediate help, (Basu, Sankanarayanan, Mandal, Roy, Das, Choudhury, Data, Karamakar, Tsu,Chakrabarti, and Siddiqi, 2002).

Cancer of the cervix is a preventable disease, and its prevention is through early detection of premalignant stages of the disease. In recent years, a screening test for cervical precancerous stage using visual inspection aided by acetic acid has been found to be a suitable low cost and a most feasible alternative modality for control of cervical cancer in developing countries (Carr and Sellors,2004). Visual inspection of the cervix with acetic acid (VIA) involves the inspection of the cervix with naked eye before and after application of 3-5\% acetic acid solution with the use of a light source (Eze, 2009).

McCarey, Pirek, Tebeu, Boulvain, Doh and Patrick (2011) further stated that creating awareness among health workers on risk factors and current methods for cervical cancer screening is necessary and good step 
towards implementing effective prevention programs. They further stated that lack of knowledge about visual inspection with acetic acid (VIA) in our population and among healthcare workers can be a prime barrier for access to cervical cancer prevention. Recent years have witnessed a significant development in cervical cancer prevention in developed countries in addition to cytology screening services. Previous efforts to implement cytology-based screening in developing countries have been conducted in the early 1980's but it has failed to reduce the mortality rates, mainly due to inadequate material resources, and lack of trained providers. In this regard, a recent cost-effective screening strategy using VIA emerged to be use, in developing countries like Nigeria.(Moon, Cordoso,Baptista,Mohsin, Sten and Vermund, 2012).In developed parts of the world, there has been a steady decline in incidence and mortality of the disease as a result of cervical screening programme. It has been possible to do this because cervical cancer is a slowly evolving disease that begins as a mild dysplasia and progresses over as many as 10 or more years to invasive carcinoma (Ijaiye, Aboyeji and Buhari, 2004).Regular cervical cancer screening for all sexually active women and treatment of precancerous tests remains the key strategy to prevent cervical cancer. The primary goal of cervical cancer screening is to detect and treat any cervical intraepithelial neoplasia (CIN) thereby preventing the occurrence of invasive cancer. Effective screening program however, have often being associated with the use of sophisticated technology and high level infrastructure and resources. Moreover, organized screening programs can be effectively implemented in limited resource settings without relying on sophisticated technologies. For example, using alternative approach has been successfully applied using visual inspection with acetic acid (VIA) to screen for precancerous lesions (Sankaranarayanan, 2002).

Adewuyi, Shittu, Rafindadi (2008) reveals that in developed countries, the use of papanikolaou (pap) smear screening has correlated strongly with a reduction in both cervical cancer incidence and mortality. Due to a lack of technical skills, human resources and the financing required to maintain effective cytology-based follow-up services, sustainable pap smear-based screening programs have not been mounted effectively in developing countries. Visual inspection of the cervix, using acetic - acid to highlight precancerous lesions so that they can be viewed with the "naked eye", shifts the identification of precancer from the laboratory to the clinic. Such procedures eliminate the need for laboratories and transport of specimens, require very little equipment and provide women with immediate test results. A range of medical professionals - doctors, nurses or professional midwives - can effectively perform the procedure, provided they receive adequate training and supervision. As a screening test, VIA may perform as well as or better than cervical cytology in accurately identifying precancerous lesions. VIA can often have significant advantages over papanicolas smear in lowreasource settings, particularly in terms of increased screening coverage, improved follow-up, care and overall program quality. Due to the needs for fewer specialized personnel and less infrastructure, training and equipment with VIA public health systems can offer cervical cancer screening in more remote (and less equipped) healthcare settings and can achieve higher coverage. Furthermore, providers can share the results of VIA with clients immediately, making it possible to screen and treat women during the same visit. This helps to reduce the number of women who may miss out any treatment because they are not able to return to the clinic at another time (Dim, 2012). Sankaranarayanon,Esmy,and Rajkumar (2007) reported that VIA can be an effective and acceptable method of cervical screening in low resource setting; they found a $25 \%$ reduction in cervical cancer incidence and a $35 \%$ reduction in mortality rate. Globally, decrease uptake of cervical cancer screening is predominantly a problem of developing countries, due to limited access to screening facilities, thereby leading to the high increased in the number of women who come up with cervical cancer. The extent to which the number of women diagnosed with cervical cancer keep on increasing has remained a matter of grave concern. It is based on this interests that the researchers intends to find out the level of awareness of nurses in Kaduna state of visual inspection of the cervix with the use of acetic acid to screen cervical cancer.

\section{Hypothesis}

There is no significant difference among the nurses demographic variables of ( Age-group, Sex, Professional category, Years of working experience and Secondary healthcare institutions) in their awareness of VIA cervical cancer screening in Kaduna-State.

\section{Methods}

The research design adopted in this study is an ex-post facto design. The research population comprises of all categories of Nurses working in the secondary healthcare institutions of Kaduna state. According to the State Ministry of Health (2013), the distribution of Nurses working in the secondary healthcare institutions of the state is 1081. A sample size of 300 was established using the Yamane, (1967) sample size selection formula.

A stratified sampling was employed to use the existing senatorial zones of Kaduna-state which were divided into northern, central and southern zones. Each stratum of the senatorial zone served as clustered according to the present existing local government areas. A purposive sampling was used to select nine (9) local 
government areas (Kaduna- South, Kaduna-North, Birnin-Gwari, Jama’a, Kauru, Kachia, Zaria, Sabon-Gari and Ikara). Proportionate sampling was used to distribute questionnaire copies to the nurses based on their number in each hospital. The nurses available were given copies of the questionnaire to fill at the selected secondary healthcare institutions ,this was employed because the researchers can easily reach out to the respondents at their various work locations.

Questionnaire designed by the researchers was the instrument used for data collection. Section A of the questionnaire sought for demographic information of the respondents while Section B aimed at assessing the awareness of VIA in cervical cancer screening by the nurses. The response to the items of the questionnaire was measured on a four interval scale. The scale was patterned along Likert format of Strongly Agree $(\mathrm{SA})=4$, Agree $(A)=3$, Disagree $(D)=2$, and Strongly Disagree $(S D)=1$.

Copies of the questionnaire were administered to the respondents at the various selected secondary healthcare institutions. The filled questionnaire copies were retrieved from the nurses at the various selected secondary healthcare institutions by the researchers within the days of administration. Three days were used to collect the data from nine secondary health care centres by three research assistants. The data collected was analyzed using descriptive statistics of frequencies and percentage for the analysis of the respondents demographic characteristics. For the analysis of variables relating to VIA by health workers, means and standard deviations were used. In the test of hypotheses, one-way Analysis of Variance (ANOVA) and t-test were used.

\section{Results}

The data analysis involves the use of means and standard deviations, this was based on the interval scale of measurement which quantified the data collected. Conclusion of the items was based on the mid-point along the four points interval scale. The mid-point used in the study is 2.5 , the value (2.5) stands for the least level of agreement on the scale while aggregate mean lower than 2.5 could thus be regarded as disagreement. The research hypothesis involved in the study was tested and analyzed with one-way analysis of variance (ANOVA), and two sample t-test at 0.05 level of significant.

Table 1:Distribution of respondent demographic variables

\begin{tabular}{|c|c|c|c|}
\hline Variables & Variable option & Frequency & Percentage $(\%)$ \\
\hline \multirow[t]{6}{*}{ Age } & $20-24$ years & 34 & 11.4 \\
\hline & $25-29$ years & 65 & 21.9 \\
\hline & $30-34$ years & 65 & 21.9 \\
\hline & $35-39$ years & 70 & 23.6 \\
\hline & 40 years and above & 63 & 21.2 \\
\hline & Total & 297 & 100.0 \\
\hline \multirow[t]{3}{*}{ Sex } & Male & 65 & 21.9 \\
\hline & Female & 232 & 78.1 \\
\hline & Total & 297 & 100.0 \\
\hline \multirow[t]{8}{*}{ Years of working experience } & $0-5$ years & 79 & 26.6 \\
\hline & $6-10$ years & 96 & 32.3 \\
\hline & $11-15$ years & 50 & 16.8 \\
\hline & $16-20$ years & 29 & 9.8 \\
\hline & 21 years and above & 41 & 13.8 \\
\hline & Total & 295 & 99.3 \\
\hline & No response & 2 & 0.7 \\
\hline & Grand total & 297 & 100.0 \\
\hline \multirow[t]{15}{*}{ Secondary healthcare institution } & i. $\quad$ Bara'u $\quad$ Dikko & 99 & 33.3 \\
\hline & Hospital Kaduna & & \\
\hline & ii. Yusuf Dantsoho Memorial & 80 & 26.9 \\
\hline & Hospital Kaduna & & \\
\hline & iii. Jibrin Mai-Gwari Memorial & 16 & 5.4 \\
\hline & & & \\
\hline & iv. Hajia Gambo & 26 & 8.8 \\
\hline & Memorial Hospital Zaria & & \\
\hline & v. Major Ibrahim B. Abdullahi & 11 & 3.7 \\
\hline & Memorial Hospital Sabon-Gari & & \\
\hline & vi. $\quad$ General Hospital Ikara & 9 & 3.0 \\
\hline & General Hospital Kafanchan & 33 & 11.1 \\
\hline & General Hospital Kauru & 8 & 2.7 \\
\hline & General Hospital Kachia & 15 & 5.1 \\
\hline & Total & 297 & 100.0 \\
\hline \multirow[t]{6}{*}{ Professional category } & Nurse & 83 & 27.9 \\
\hline & Midwife & 29 & 9.8 \\
\hline & Nurse-Midwife & 180 & 60.6 \\
\hline & Total & 292 & 98.3 \\
\hline & No response & 5 & 1.7 \\
\hline & Total & 297 & 100.0 \\
\hline
\end{tabular}


Table 1 of the study reveals age range of the respondents, $11.4 \%$ of the respondents fall within the age range of 20-24 years. $21.9 \%$ are within the range of 25-29 years. Another $21.9 \%$ falls within the age range of 30-34 years. Respondents with 35-39 age range have a percentage of $23.6 \%$, while those from 40 years and above accounted for $21.2 \%$. Among the respondents, male accounted for $21.9 \%$ while females accounted for $78.1 \%$. Subjects with (0-5 years) of working experience were $26.6 \%$, followed by subject with (6-10 years) of working experience $32.3 \%$. those with (11-15 years) of working experience were $16.8 \%$ while those with (16-20 years) of working experience accounted for $9.8 \%$. subjects with (21 years and above) working experience were 13.8, while those that did not respond to the question were $0.7 \%$. The table indicated that $33.3 \%$ of the respondents were in Bara'u Dikko Specialist Hospital Kaduna, 26.9\% were in Yusuf Dan tsoho Memorial Hospital Kaduna, 5.4\% were in Jibril Mai-gwari Memorial Hospital, Birinin Gwari. Those in Hajia Gambo Sawaba Memorial Hospital Zaria were 8.8\%, subjects in Major Ibrahim B. Abdullahi Memorial Hospital SabonGari were 3.7\%, while those in General Hospital Ikara were 3.0\%. the percentage score of those working in General Hospital Kafanchan were $11.1 \%$, those in General Hospital Kauru were $2.7 \%$, while those in General Hospital Kachia accounted for $5.1 \%$. Concerning the professional category of the respondents, the table revealed that $27.9 \%$ are registered Nurses, $9.8 \%$ are registered Midwife, while majority of the respondents have double qualification of Nurse-Midwife are $60.6 \%$.

Table 2: Summary of ANOVA on age, professional category, years of working experience and secondary healthcare institutions in the awareness of VIA

\begin{tabular}{|c|c|c|c|c|c|}
\hline Source & Sum of square & Df & Mean square & F-value & Sig \\
\hline \multicolumn{6}{|l|}{ Age } \\
\hline Between groups & 3.507 & 4 & 0.877 & 2.421 & 0.049 \\
\hline Within groups & 105.732 & 292 & 0.362 & & \\
\hline Total & 109.239 & 296 & & & \\
\hline \multicolumn{6}{|c|}{ Professional category } \\
\hline Between groups & 1.374 & 4 & 0.344 & 1.367 & 0.245 \\
\hline Within groups & 73.349 & 292 & 0.251 & & \\
\hline Total & 74.723 & 296 & & & \\
\hline \multicolumn{6}{|c|}{$\begin{array}{l}\text { Years of working } \\
\text { experience }\end{array}$} \\
\hline Between groups & 2.224 & 4 & 0.556 & 2.082 & 0.083 \\
\hline Within groups & 75.303 & 282 & 0.267 & & \\
\hline Total & 77.527 & 286 & & & \\
\hline \multicolumn{6}{|c|}{$\begin{array}{l}\text { Secondary health care } \\
\text { institution }\end{array}$} \\
\hline Between groups & 4.289 & 4 & 1.072 & 2.800 & 0.023 \\
\hline Within groups & 109.893 & 287 & 0.383 & & \\
\hline Total & 114.182 & 291 & & & \\
\hline
\end{tabular}

(F- Critical $=2.37, \mathrm{p}<0.05)$

(F-Critical $=2.37, \mathrm{p}<0.05)$

$(\mathrm{F}-\mathrm{Critical}=2.37, \mathrm{p}>0.05)$

$(\mathrm{F}-$ Critical $=2.37, \mathrm{p}<0.05)$

Table 2 above reveals an observed levels of significance $(\mathrm{P})$ for the test is less than $0.05(\mathrm{P}<0.05)$ for age, professional category and secondary healthcare institutions. Therefore the null hypothesis stating that there is no significance difference among the healthcare workers demographic variables on this three data of in their awareness of VIA in cervical cancer screening in Kaduna State is rejected. While an observed level of significant $(p)$ for the test is higher than $0.05(\mathrm{p}>0.05)$ for years of working experience. This means that the subjects did not differ significantly base on years of working experience in the awareness of VIA in cervical cancer screening in Kaduna State.

Table 3: Two sample t-test on awareness of VIA equal variances assumed

\begin{tabular}{|l|l|l|l|l|l|l|l|}
\hline Sex & N & Mean & Std. deviation & Std. error & t-value & Df & Sig \\
\hline Male & 65 & 2.4911 & 0.53237 & 0.06603 & 4.038 & 295 & 0.000 \\
\hline Female & 232 & 2.1554 & 0.60795 & 0.03991 & & & \\
\end{tabular}

$(\mathrm{t}$-critical $=1.645, \mathrm{DF}=295, \mathrm{p}<0.05)$

Table 3, shows the observed t-value for the test (4.038) which is greater than the t-critical of (1.645) indicated at the bottom of the table. The observed significant level for the test is $(0.000)(\mathrm{P}<0.05)$. This means there is significance difference between male and female subjects in their awareness of VIA cancer screening in Kaduna State. 
Awareness of Visual Inspection with Acetic-Acid (Via) In Cervical Cancer Screening Among ....

\begin{tabular}{|c|c|c|c|}
\hline S/N & Awareness of VIA & Mean & Standard Deviation \\
\hline 1. & I head of VIA in my place of work & 1.3939 & 0.82368 \\
\hline 2. & I understand the concept of VIA & 2.1954 & 0.88369 \\
\hline 3. & $\begin{array}{l}\text { VIA is a simple procedure that can be done by health } \\
\text { worker in the hospital }\end{array}$ & 2.3039 & 0.92993 \\
\hline 4. & VIA can only be done in a specialist hospital & 2.2226 & 0.88521 \\
\hline 5. & $\begin{array}{l}\text { VIA is an alternative method of cervical cancer } \\
\text { screening }\end{array}$ & 2.4735 & 0.96122 \\
\hline 6. & VIA can be affordable by women in a rural society & 2.1139 & 0.78457 \\
\hline 7. & The VIA procedure is time consuming always & 2.2239 & 0.76086 \\
\hline 8. & One of the major requirement for VIA is acetic acid & 2.4242 & 1.24736 \\
\hline 9. & $\begin{array}{l}\text { Positive VIA screening test means the presence of aceto } \\
\text { white cells in the cervix }\end{array}$ & 2.5091 & 0.78472 \\
\hline 10. & $\begin{array}{l}\text { Further management becomes necessary in case of } \\
\text { positive VIA screening }\end{array}$ & 2.6679 & 0.85950 \\
\hline & Aggregate mean score & 2.2288 & 0.60749 \\
\hline
\end{tabular}

Table 4, revealed the aggregate mean of 2.2288 which is less than 2.5 of the decisive mean. Thus it indicated lack of awareness of VIA among nurses in the secondary health care institutions of Kaduna State.

\section{Discussion}

The researchers examined the awareness of visual inspection with acetic acid (VIA) among nurses in secondary healthcare institutions of Kaduna State.

Table 1 revealed the demographic variables of the respondents. The table shows the ages of the subjects that cut across various age group with more concentration in 35-39 years age-range. The percentage score for the range (35-39 years) is $23.6 \%$ of the total number of subjects involved in the study. The remaining subjects could be said to be fairly distributed as indicated in the table. The fairly distribution of subjects that cut across the various age-group could be attributed to the fact there is social awareness on the importance of people to join the medical services because of the increase demand of healthcare by the community members. There is a high discrepancy between the proportion of male and female subjects. The males accounts for $(21.9 \%)$ while the females accounts for $(78.1 \%)$. This difference could be related to the fact that nursing is a profession dominated by females. On the years of working experience of the subjects, the table shows that those with 6-10 years of experience equivalent to $(32.3 \%)$ have the highest percentage score among the respondents. This reflects the policy of the state government in some medical/nursing schools to absorbed the students into the general hospitals immediately they graduates from their respective schools. They usually worked in the general hospitals for a specified period of time. Health workers who are working in Barau Dikko specialist hospital Kaduna have the highest percentage score of $(33.3 \%)$ of the total respondents. The large number of subjects from this particular institution could be due to location of the hospital as it is situated in Kaduna metropolis, created since during the northern region and it has now being converted to a teaching hospital. The proportion of health workers in other secondary healthcare institutions were fairly distributed and could therefore be expected to give valid information about the activities in the centres, concerning the professional category of the respondents, (Nurse-Midwife) that is subjects that have double qualification of Nursing and Midwifery have the highest percentage score of $(60.6 \%)$. By this distribution, all the categories of nurses in the secondary healthcare institutions could be said to be fairly distributed.

In the test of the hypothesis of the study looking at table 2, a significant difference was established between age-group, professional category and secondary healthcare institutions in the awareness of VIA by the nurses. But no significant difference observed between years of working experience and awareness of VIA by the nurses. To determine where the difference lies, the scheffe post-hoc test shows that nurse/midwife and nurses differ significantly, this contradicts the findings to sankaranarayanan et al, (2008) whom stated that nurses are equally trained to provide VIA services in developing countries. Also all the secondary healthcare institutions as used in the study differ significantly in their awareness of VIA. On the issue of sex of the respondents and awareness of VIA, the t-test reveals a significant difference between male and female subject in their awareness of VIA as indicated in table 3 of the study. These differences could be attributed to the fact that female nurses are more engage in the areas of obstetric and gynecology compare to their male counter parts. 
Table 4 reveals the nurses awareness of VIA. The aggregate mean score of (2.2288) shows that the respondents are not aware of VIA in cervical cancer screening. On the contrary moon, Cordoso, Baptista, Moshin, Ster and Vermund (2012) reveals that clinic nurses and hospital physicians are aware of using VIA to screen for cervical cancer, as VIA procedure was taught to clinic nurses and hospital physician with a regular clinical feedback for quality evaluation and retraining. Most of the subjects as identified in the study have not heard of VIA in their places of work, that is the hospitals, as such, most of them did not understand the concept behind it. They were of the view that VIA can only be done in a specialist hospital and the subjects were not aware that it can be an alternative method of cervical cancer screening to cytology screening procedures. The findings of the study shows that the subjects are not aware that VIA is cheap and effective method of cervical cancer screening, and the time spent to do the procedure is less, thereby making it to be consumer friendly. To further reflect on the unawareness of VIA among the health workers, the subjects were not aware that acetic acid is the major requirement needed for VIA screening procedure. This findings supported the work of Mc Carey, Pirek, Tebeu, Boulvaln, Doh and Petigna (2011) who stated that health workers are not aware of the use of VIA to screen for cervical cancer. Many respondents with mean score of (2.1138) in the study believed that screening uptake in the general population is poor because it is too expensive, this further reflects the lack of awareness of the health workers in VIA in cervical cancer screening. The lack of awareness of VIA among the nurses as identified in the study is not new, it is also identified by Kolawole (2011), in a survey carried out in Ahmadu Bello University Teaching Hospital Shika among female health workers. The study shows that only (2.1954) of the respondents are aware that visual inspection with the use of acetic acid can be done to screen for cervical cancers. Furthermore, The World Health organization (2012) reveals that the level of awareness of visual inspection with acetic acid is low, therefore, the need to increase the awareness level is necessary. The only areas where subjects reflect awareness of VIA is where they agree that positive VIA screening means the presence of aceto-white cells in the cervix. Another area that capture on awareness as it regards to VIA is the issue of further management in case of positive VIA screening, most of the subjects view the management as necessary.

\section{Conclusion}

Nurses in secondary health care institutions of Kaduna State are not aware of using VIA in cervical cancer screening. This adversely lead to poor uptake of the screening service among women of child bearing age as the incidence of Human Papilloma Virus is more prominent among the age-group. In view of this findings, the state hospitals management board in collaboration with the National Association of Nigerian Nurses and Midwives (Kaduna State chapter) should mount awareness campaign for nurses through seminars and workshops due to negative awareness level of the nurses on VIA.

\section{References}

[1]. Adewuyi S.A., Shittu S.O., and Rafindadi A.H. (2008). Socio-demorgraphic and Clinical Characterization of Cervical Cancers in northern Nigeria. European journal of gynaecol oncology.2961-4 PMID; 18386466.

[2]. Adewole, I.F., Benedict, J.C., Brain, C.T., and Follen, M.(2005). Evolving a strategic approach to cervical cancer control in Africa. Gynaecologic Oncology. (vol) 99; pp S 209-S212.

[3]. Basu P., Sankanarayanan R., Mandal R., Roy C., Das P., Choudhury D, Datta K, Karamakar S, Tsu V, Chakrabarti R.N., and Siddiqi M.(2002). Evaluation of downstaging in the detection of cervical neoplasia in kolkata india. International Journal of Cancer (2002) July 1:1000(1):92-6 (PubMed).

[4]. Carr, K.C., and Sellors, J.W.,(2004).Cervical cancer screening in low resource settings; using visual inspection with acetic acid. Journal of Midwifery Womens Health (2004); 49(4); pp 329-337. Pub med.

[5]. Dim,C.C.(2012).Improving cervical screening in Nigeria; A review of the basics of neoplasm and cytology practice. Nigerian journal of clinical practice. Volume 15(3) pp 247-252. Available at http:// www.njcp online.com/text.asp? retrieved on 5/3/2013

[6]. Eze, B.(2009). Awareness and uptake of cervical screening in owerri, south eastern Nigeria...Annals of African Medicine (2009). (Vol) 6: issue 3 pp 94-98.

[7]. Ijaiye M.A., Aboyeji M.O., and Buhari A.(2004).Cervical cancer staging. West African Journal of midwifery. Volume 23. NO 4. October 2004.pp 105-110.

[8]. Kolawole, A.O.(2008).Cervical cancer and its control in Nigeria; Challenges and the way forward. KIT( Royal Tropical Institute)/ Development policy and practice. Vrije university ,Amsterdam, The Netherlands.An unpublish thesis.

[9]. McCarey, C., Pirek, D., Tebeu, P.M.,Boulvain, M., Doh, A.S., and Patrick, P.(2011).Awareness of HPV and Cervical prevention among Cameroonian healthworkers. Available at http://www.biomedcentral.com/1472-6874/11/45.

[10]. Moon T.D., Cardoso, A.,Baptista, A.J., Mohsin S., Sten H., and VermundT.(2012). Implementation of cervical cancer screening using visual inspection with acetic acid in rural Mozambique; success and challenges using HIV care and treatment programme investment $\mathrm{s}$ in Zambia province. Journal of the International AIDS Society (2012),pp15-17. http://www.Jiasociety.org/content/15/2/17406/http://dx.doi.org/10.7448/IAS.15.2.1706.

[11]. Sankaranarayanan R., Esmy P.O., and Rajkumar R.(2007). Effect of Visual Screening on cervical cancer incidence and mortality in Tamil Nadu,India: a cluster-randomised trial. Lancet (2007): 370 pp398-406.(PubMed)

[12]. World Health Organization (2012).Cervical cancer screening in Developing Countries. Report of a WHO Consultation 2012.

[13]. World Health Organization(2013). Prevention of cervical cancer through screening using visual inspection with acetic acid (VIA) and treatment with cryotherapy; A demonstration project in six African countries; ( Malawi, Madagascar, Nigeria,Uganda, the United Republic of Tanzania, and Zambia). ISBN 9789241503860 (NLM Classification; WP 480) Geneva, Switzerland.WHO Document production services.

[14]. Yamane, T. (1967). 'Statistics; an introductory analysis', Newyork; Harper and Row. 